Article

\title{
Bond Behavior of CFRP/Steel Double Strap Joint at Elevated Temperatures
}

\author{
Na Li ${ }^{1,2}$, Shan $\mathrm{Li}^{2 *}$, Chun Liu ${ }^{2}$ and Tao Zhu ${ }^{2}$ \\ 1 School of Civil Engineering and Architecture, Wuhan University of Technology, Wuhan 430070, China; \\ ln 950228@163.com (N. L.); \\ 2 School of Civil Engineering, Wuhan University, Wuhan 430072, China ; lishan@whu.edu.cn (S. L.); \\ 330622309@qq.com (C. L.); dino2088@hotmail.com (T. Z.). \\ * Correspondence: lishan@whu.edu.cn; Tel.: +86-27-6877-5832
}

\begin{abstract}
Carbon fiber reinforced polymer (CFRP) has been used widely in strengthening of steel structures. Steel/CFRP systems subjected to elevated temperatures is realistic in a summer climate event in many countries where the temperature in steel may approach $50{ }^{\circ} \mathrm{C}$ or even higher, which will lead to the degradation of the bond performance between CFRP and steel. Therefore, predicting the bond behavior of the CFRP/steel system under elevated temperature is critical. This paper investigated the mechanical performance of CFRP/steel adhesively-bonded double strap joints at elevated temperatures. Thirty CFRP-steel double strap joints were tested to failure under temperatures between $10^{\circ} \mathrm{C}$ and $90{ }^{\circ} \mathrm{C}$. It was found that the joint failure mode changed from adherend failure to debonding failure as the temperature approached $\mathrm{Tg}$. In addition, the ultimate load and joint stiffness decreased significantly at temperatures near to and greater than $T_{\mathrm{g}}$. Based on the experimental results, a model is proposed to predict the bond stress of the CFRP/steel at different temperatures.
\end{abstract}

Keywords: CFRP/steel; bond behavior; elevated temperatures; bond stress

\section{Introduction}

The use of externally bonded fibre-reinforced polymer (FRP) composites to rehabilitate deteriorating steel structures in civil engineering has received considerable attention due to the excellent properties, such as high strength-to-weight ratio and flexibility in adapting to field configurations [1-3]. Fiber-reinforced polymer (FRP) plate strengthening relies critically upon the adequate bond strength between the FRP and the steel, which ensures the coordination of the FRP and the existing structures, thus obtaining a effective strengthening [4]. Extensive research has been conducted on the bond behaviour of CFRP and steel at ambient temperature experimentally and theoretically [5-13].

However, steel/FRP systems subjected to elevated temperatures is realistic on the structural surface where the temperature may approach $50{ }^{\circ} \mathrm{C}$ or even higher, if it is directly exposed to sunlight in a typical summer climate [14]. The commonly used adhesive has glass transition temperatures $\left(T_{\mathrm{g}}\right)$ between $40{ }^{\circ} \mathrm{C}$ and $70{ }^{\circ} \mathrm{C}$ [15]. The glass transition displays "softening" of the adhesive as it changes from a glassy state to a rubbery state, and this does not occur at a single 
temperature, and the stiffness and strength of the adhesive may decrease considerably before $T_{\mathrm{g}}$ has been reached $[16,17]$. The mechanical degradation of adhesive may led to a reduction in the mechanical properties of the resulting FRP composites [18,19]. This behavior becomes more significant for resin-dominated properties than for the fiber-dominated properties [20]. Thus, for a steel structure strengthened with FRP composites under elevated temperatures, not only the FRP composites in such structures degrade at elevated temperatures [21], but also the adhesive layer between FRP composites and steel is at high risk [22]. Such a mechanical degradation of structural adhesives always results in the failure of adhesively-bonded CFRP/steel joints in this critical temperature range.

Research into the elevated temperature performance of FRP strengthening has been conducted on the "hot" temperatures that occur during fire [23] and "warm" temperatures [24]. Klamer et al. [25] tested FRP-strengthened concrete beams at $20^{\circ} \mathrm{C}, 50^{\circ} \mathrm{C}$, and $70^{\circ} \mathrm{C}$ and showed that while the performance of the FRP strengthening was not adversely affected at $50{ }^{\circ} \mathrm{C}$, the load capacity was significantly reduced at $70^{\circ} \mathrm{C}$. Zhu et al. [26] studied the thermal-mechanical behavior of CFRP/Steel single-lap shear joints and found that when the temperature exceeded the glass transition temperature of the adhesive, bond strength and interfacial fracture energy both decreased significantly. In addition, the failure modes of the joints changed with the temperature, which reflects the degradation of the bond properties. Al-Shawaf et al. [14] reported that when the temperature exceeded $60{ }^{\circ} \mathrm{C}$, the residual strength of adhesively-bonded steel/CFRP double strap joints (using Araldite 420 as epoxy adhesive) was about $22 \%$ of their initial strength measured at ambient condition. Nguyen et al. [27,28] investigated the mechanical performance of steel/CFRP adhesively-bonded double strap joints at elevated temperatures around the glass transition temperature $\left(T_{g}=42{ }^{\circ} \mathrm{C}\right)$ of the adhesive. The results showed that the joint failure mode changed from adherend failure to debonding failure as the temperature approached $T_{\mathrm{g}}$. The ultimate load and joint stiffness decreased significantly at temperatures near to and greater than $T_{\mathrm{g}}$, decreasing by $80 \%$ when temperature reached only $60^{\circ} \mathrm{C}$. It can be verified that the mechanical performance of steel/CFRP double strap joints subjected to elevated temperatures may be largely dominated by that of the adhesive. Agarwal et al. [29] studied the behavior of steel-CFRP joints under the combined sustained load and temperature cycle. In this study, a new adhesive with a glass transition temperature $\left(T_{\mathrm{g}}\right)$ of $82{ }^{\circ} \mathrm{C}$. The results revealed no failure in the joint during exposure to thermal cycling between $10{ }^{\circ} \mathrm{C}$ and $50{ }^{\circ} \mathrm{C}$ and little degradation in the residual bond strength. And it is recommended that the $T_{\mathrm{g}}$ of the adhesive should be at least $30^{\circ} \mathrm{C}$ greater than the highest service temperature in order to avoid failure under thermo-mechanical loading.

In this paper, a series of adhesively-bonded steel/CFRP double strap joints was examined in tension at temperatures between $10{ }^{\circ} \mathrm{C}$ and $90{ }^{\circ} \mathrm{C}$. The temperature dependence of joint stiffness and strength were evaluated by comparing those properties with the values at $30^{\circ} \mathrm{C}$. To verified the critical influence of adhesive layer, the mechanical properties of the used epoxy adhesives and the CFRP plates were also tested at the elevated temperatures. Based on the results, a model for predicting the shear stress under different temperatures are proposed. The modelling results compare well with the experimental data presented in this paper. In addition, this paper also examines the change of failure modes for steel/CFRP joints at elevated temperatures. 


\section{Experimental program}

There were two test series in the experimental program, including material testing and CFRP/steel double strap joints testing. Both tests were conducted at elevated temperatures from $10{ }^{\circ} \mathrm{C}$ to $90{ }^{\circ} \mathrm{C}$. In the material testing, the tension tests were conducted to characterize the temperature effects on the material properties of CFRP plates and epoxy adhesive. In the CFRP/steel double strap joints testing, the interface behavior between CFRP plates and steel plates at elevated temperatures was investigated. The two test series will be described in the following sections.

\subsection{Material testing of epoxy adhesive under elevated temperatures}

The schematic view of epoxy adhesive adopted in this study is shown in Figure 1, where their geometry is defined according to GB/T 2567-2008 [30]. All adhesive coupons used for tensile tests were fabricated by pouring the homogeneous mixture into plexiglass molds, cured for 2 weeks at ambient temperature and tested according to ISO527-2-1993 [31], as shown in Figure 2. These coupons are divided into five groups and tested at five different temperatures (see Table 1).

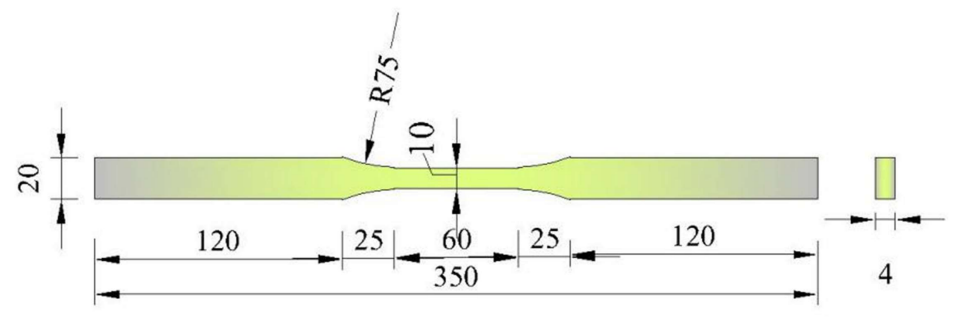

Figure 1. Schematic view of epoxy adhesive coupon.

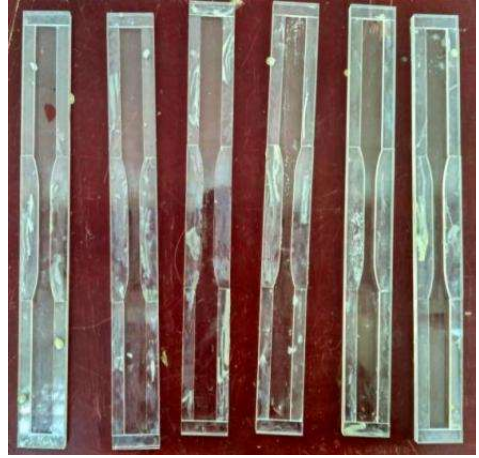

(a)

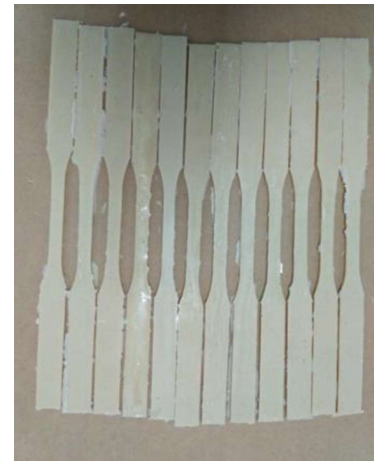

(b)

Figure 2. Photograph of the specimens: (a) plexiglass mold; (b) adhesive coupons.

Table 1. Details of the adhesive coupons and the test results.

\begin{tabular}{ccccccc}
\hline $\begin{array}{c}\text { Specimen } \\
\text { ID }\end{array}$ & $\begin{array}{c}\text { Specimens } \\
\text { number }\end{array}$ & $\begin{array}{c}\text { Temperature } \\
/{ }^{\circ} \mathrm{C}\end{array}$ & $\begin{array}{c}\text { Ultimate load } \\
/ \mathrm{kN}\end{array}$ & $\begin{array}{c}\text { Tensile strength } \\
/ \mathrm{MPa}\end{array}$ & $\begin{array}{c}\text { Modulus } \\
/ \mathrm{GPa}\end{array}$ & $\begin{array}{c}\text { Elongation } \\
/ \%\end{array}$ \\
\hline $\mathrm{A}-\mathrm{T} 10$ & 6 & 10 & 1354 & 33.85 & 4788 & 2.4 \\
\hline
\end{tabular}




\begin{tabular}{lllcccc}
\hline A-T30 & 6 & 30 & 1669 & 41.72 & 5052 & 5.2 \\
A-T50 & 6 & 50 & 474 & 11.85 & - & 26.6 \\
A-T70 & 6 & 70 & 89 & 2.23 & - & 38.4 \\
A-T90 & 6 & 90 & 38 & 0.95 & - & 43.3 \\
\hline
\end{tabular}

\subsection{Material testing of CFRP plates under elevated temperatures}

The schematic view of CFRP coupons adopted in this study is shown in Figure 3. The geometry in Figure 3 is defined according to GB/T 3345-1999 [32]. A total of 30 specimens were fabricated, as shown in Figure 4a, and cured at ambient temperature for 2 weeks. Aluminum tabs were glued at both ends of the specimen to reduce the stress concentration and distribute the force uniformly to the CFRP plates. These tabs were sand-blasted and cleaned with acetone, a thin layer of adhesive was applied on their surface, and then they were attached at both ends of the CFRP plates on both sides.

Strain gauges with a working temperature of $-30 \sim 120{ }^{\circ} \mathrm{C}$ were mounted at the middle of the CFRP coupons to measure the strains, as shown in Figure 4b. These specimens were divided into five equal groups and tested at different temperatures (see Table 2).

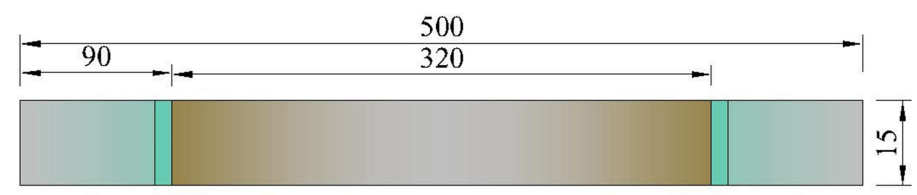

(a)

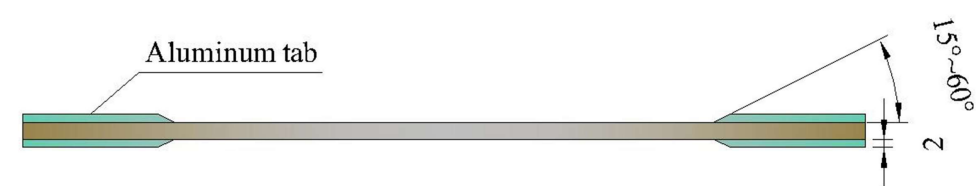

(b)

Figure 3. Schematic view of CFRP plate coupon: (a) front view; (b) side view.

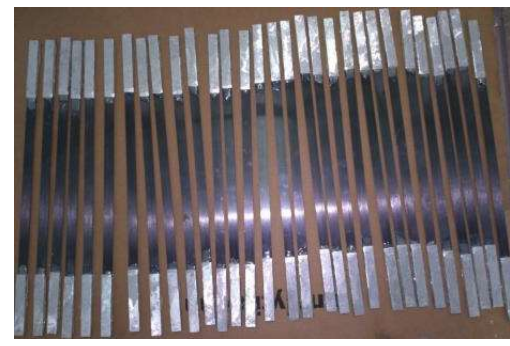

(a)

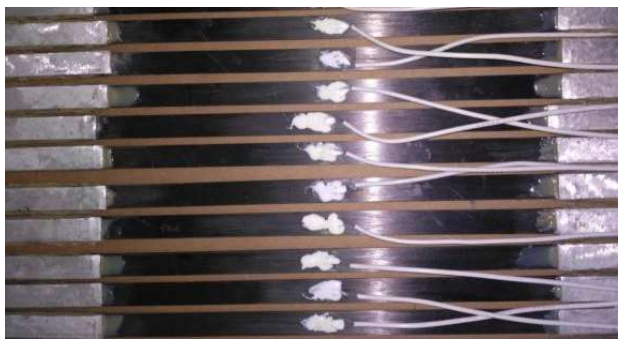

(b)

Figure 4. Photograph of the coupons: (a) CFRP plate coupon; (b) the location of strain gauge. 
Table 2. Details of the CFRP plate coupons and the test results.

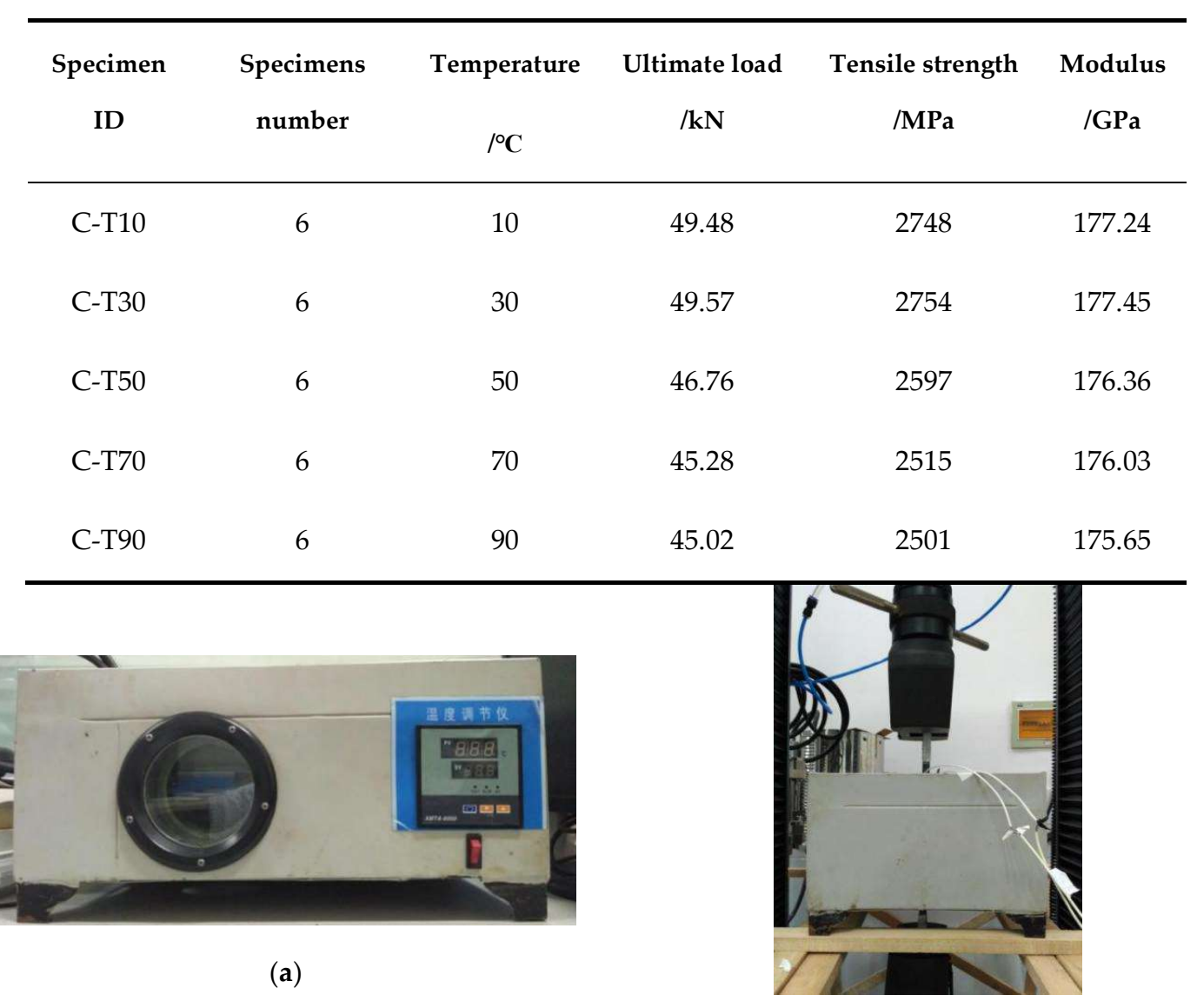

(b)

Figure 5. Test setup: (a) temperature chamber; (b) specimens setup.

\subsection{Bond testing of CFRP-steel double strap joint under elevated temperatures}

Figure 6 shows the details of CFRP-steel double strap joint, which includes inside steeladherend, out CFRP plate adherend and the adhesive layer in between. The surfaces of the steel places were sandblasted and cleaned with acetone to remove grease, oil and rust. Each steel/CFRP double strap joint was fabricated from two steel plates joined together by CFRP plates. The joints were formed using a wet lay-up method. All coupons were cured for 2 weeks at room temperature. A total of 30 coupons were divided into five equal groups and tested at 10, 30, 50, 70 and $90{ }^{\circ} \mathrm{C}$, as shown in Table 3.

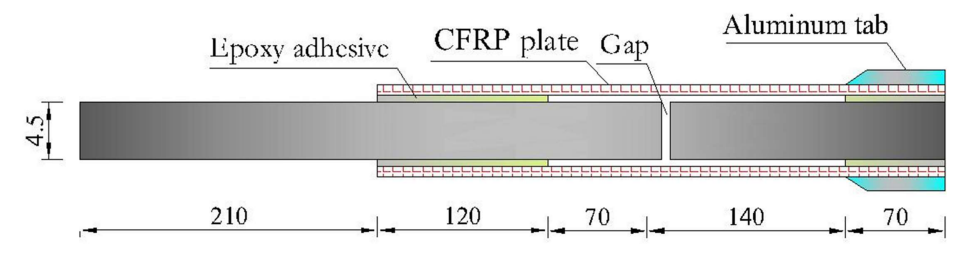

(a) 


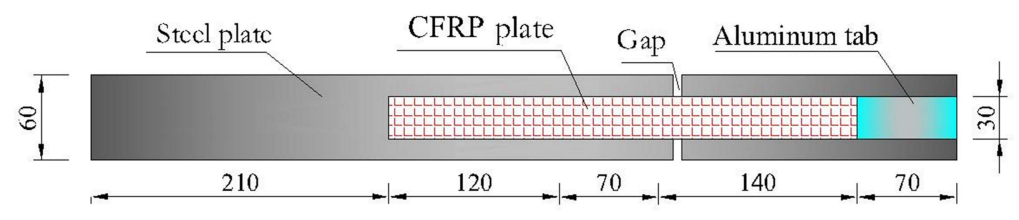

(b)

Figure 6. Schematic view of CFRP/steel double strap joint: (a) front view; (b) side view.

Table 3. Details of CFRP/steel double strap joint and test results.

\begin{tabular}{cccccccccc}
\hline Specimen & Temperature & \multicolumn{9}{c}{ Ultimate load /kN } & \multicolumn{2}{c}{ Average value } \\
\cline { 3 - 8 } ID & $1{ }^{\circ} \mathbf{C}$ & 1 & 2 & 3 & 4 & 5 & 6 & /kN \\
\cline { 3 - 8 } C/S-T10 & 10 & 24 & 23.2 & 22.95 & 15.95 & 25.25 & 22.75 & 22.35 \\
C/S-T30 & 30 & 24.35 & 42.5 & 34.6 & 40.65 & 38.65 & 34.75 & 35.92 \\
C/S-T50 & 50 & 20.55 & 15.75 & 24.95 & 16.4 & 10.1 & 15 & 17.13 \\
C/S-T70 & 70 & 10.25 & 11.95 & 9.85 & 10.1 & 6.8 & 8.5 & 9.58 \\
C/S-T90 & 90 & 2.45 & 3.8 & 4.7 & 6.25 & 3 & 5.5 & 4.28 \\
\hline
\end{tabular}

Strain gauges with a working temperature of $-30 \sim 120{ }^{\circ} \mathrm{C}$ were mounted on the top surface of the CFRP plates, as shown in Figure 7. The strain gauges at the extreme locations were bonded at 5 $\mathrm{mm}$ of the CFRP loaded end and $15 \mathrm{~mm}$ of the CFRP free end. The remaining intermediate gauges were $20 \mathrm{~mm}$ spaced apart. A data logger was used to collect the axial strains developed throughout the CFRP plates during the test. The slip between the loaded end of CFRP and the steel plates by LVDT, as shown in Figure 8.
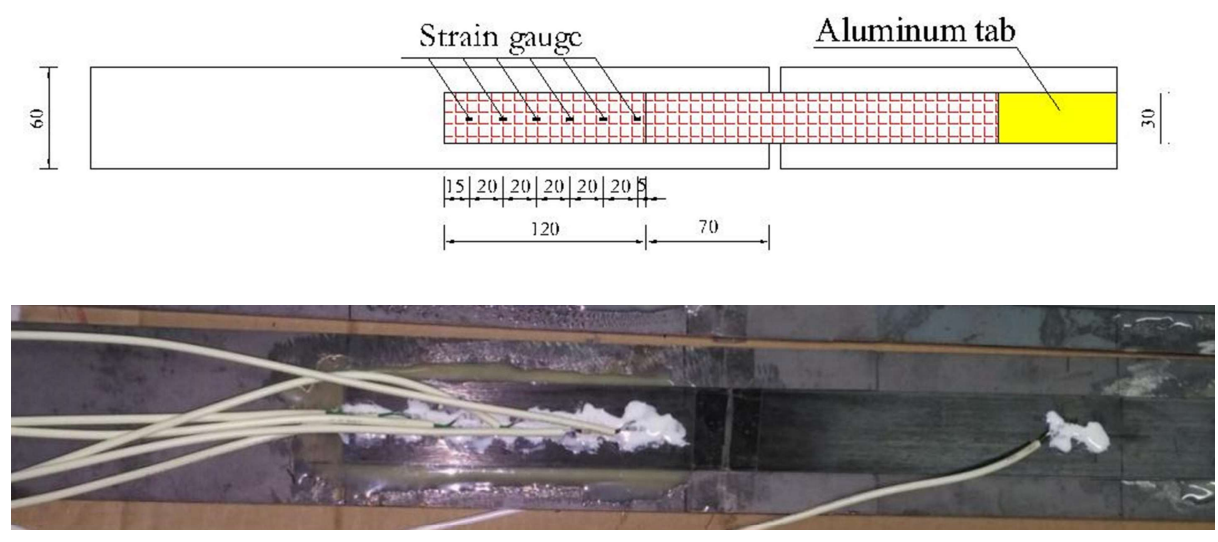

Figure 7. The arrangement of the strain gauges in CFRP/steel double strap joint. 

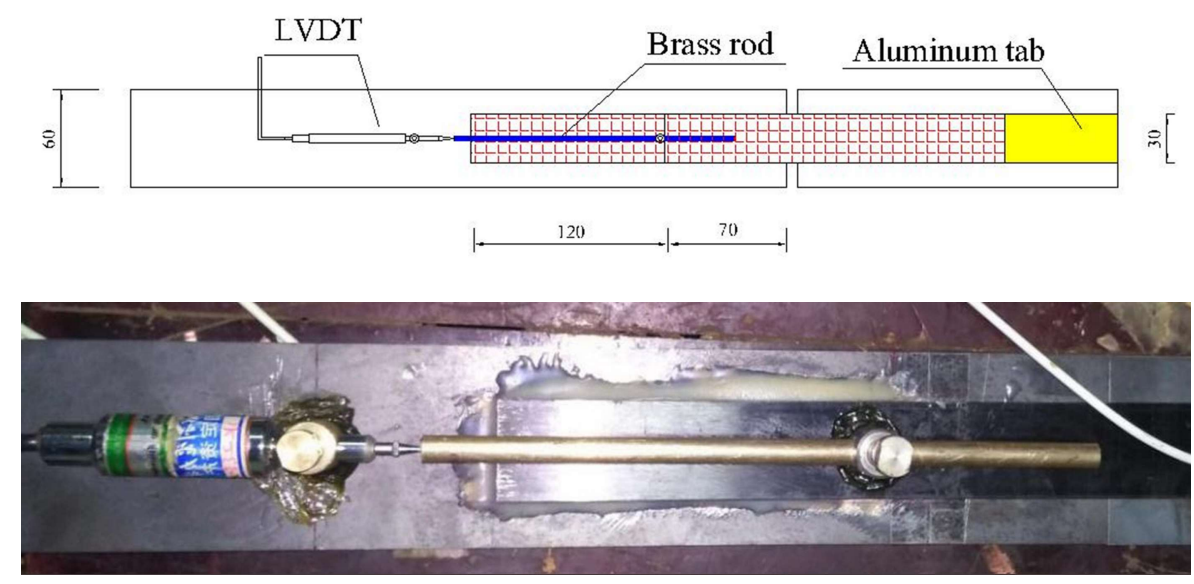

Figure 8. The arrangement of the LVDT in CFRP/steel double strap joint.

\section{Experimental results and discussions}

\subsection{Effect of elevated temperatures on the properties of epoxy adhesive}

The epoxy adhesive coupon under different temperatures all ruptured at the middle range, as shown in Figure 9. The difference is that the coupons at higher temperatures experienced a much larger deformation due to the softening.

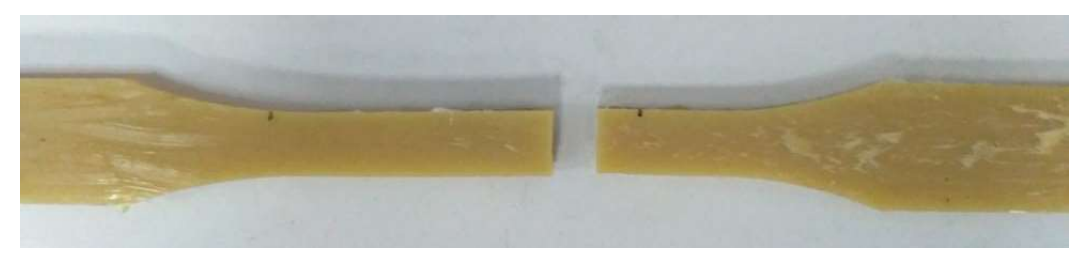

Figure 9. Failure mode of the epoxy adhesive coupon under tension.

The test results are summarized in Table 1 . When the temperatures exceeded $50{ }^{\circ} \mathrm{C}$, the modulus of the epoxy adhesive was not measured due to the softening and creep. The effects of temperature on the tensile strength and elongation of epoxy adhesive are shown in Figure 10. When the temperature increased from $10^{\circ} \mathrm{C}$ to $30^{\circ} \mathrm{C}$, there was a obvious increase in the tensile strength. However, with a further increasing of temperature, the tensile strength had a sharp decrease, being close to $0 \mathrm{MPa}$ at $90{ }^{\circ} \mathrm{C}$. As for the elongation, there is a slight increase when the temperature was below $30^{\circ} \mathrm{C}$, beyond which the elongation increased significantly. 


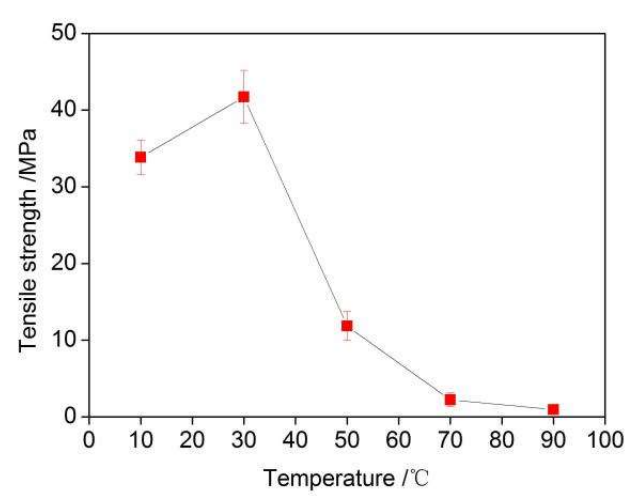

(a)

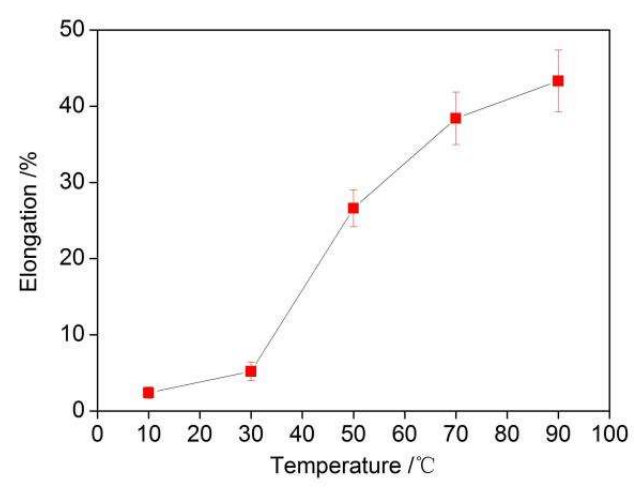

(b)

Figure 10. The effect of elevated temperature on the properties of epoxy adhesive: (a) tensile strength; (b) elongation.

\subsection{Effect of elevated temperatures on the properties of CFRP plates}

The test observations and the failure modes changed with temperatures. For the coupons at $10{ }^{\circ} \mathrm{C}$ and $30{ }^{\circ} \mathrm{C}$, several sounds due to the rupture of carbon fibers can be heard when the coupons were much close to failure. When the temperature was $50{ }^{\circ} \mathrm{C}$, more sounds can be heard before failure. As for the coupons at $70{ }^{\circ} \mathrm{C}$ and $90{ }^{\circ} \mathrm{C}$, the sound can be heard when the load reached $80 \sim$ $85 \%$ of the ultimate load. This indicted that the CFRP failed with the carbon fibers being stretched separately, without effective load transferring between carbon fibers, at higher temperatures .

Figure 11 shows the failure modes of the CFRP coupons at different temperatures. From Figures 11a and $\mathrm{b}$, it can be seen that the CFRP plated at $10{ }^{\circ} \mathrm{C}$ and $30{ }^{\circ} \mathrm{C}$ ruptured with several hanks. When the temperatures were $70{ }^{\circ} \mathrm{C}$ and $90{ }^{\circ} \mathrm{C}$, the CFRP plates seems to be separated into a number of CFRP bundles and ruptured with a explosive mode, as shown in Figures $11 \mathrm{~d}$ and e, respectively. The different phenomena can be explained that with the increasing of temperature, the epoxy adhesive gradually soften and the shear strength decreased. Consequently, the epoxy adhesive gradually failed to transfer the load between the carbon fibers, and the carbon fibers were stretched to rupture separately.

The test results of CFRP coupons are summarized in Table 2. Figure 12 shows the effect of elevated temperature on the properties of CFRP plates in terms of tensile strength. When the temperature increased from $10{ }^{\circ} \mathrm{C}$ to $30{ }^{\circ} \mathrm{C}$, the tensile strength and modulus had no change. However, compared to the tensile strength at $30^{\circ} \mathrm{C}$, the ultimate strength of the coupons under $50^{\circ} \mathrm{C}$, $70^{\circ} \mathrm{C}$ and $90^{\circ} \mathrm{C}$ decreased by $5.50 \%, 8.68 \%$ and $9.01 \%$, respectively. The modulus of the CFRP plates experienced a very slight decrease when the temperature increased from $10^{\circ} \mathrm{C}$ to $90{ }^{\circ} \mathrm{C}$. 


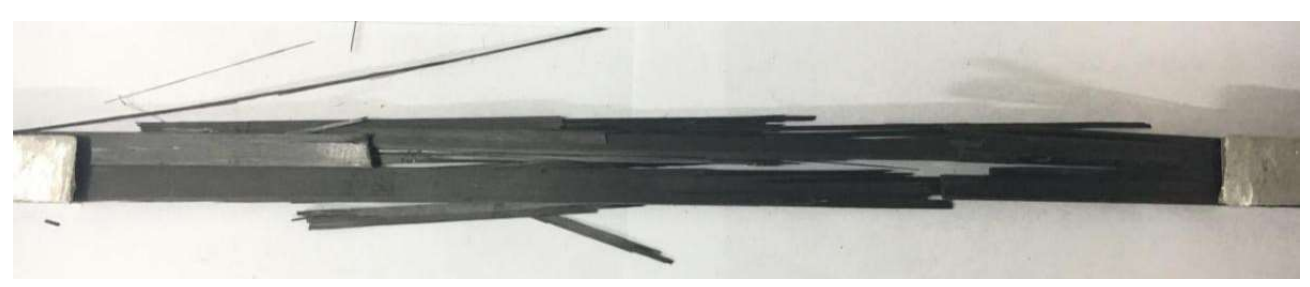

(a)

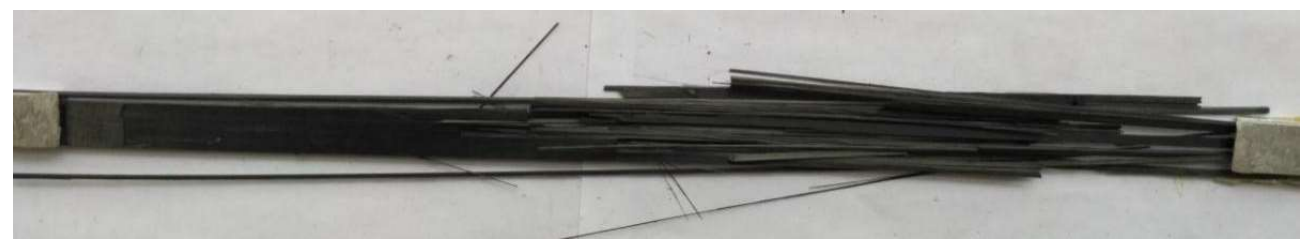

(b)

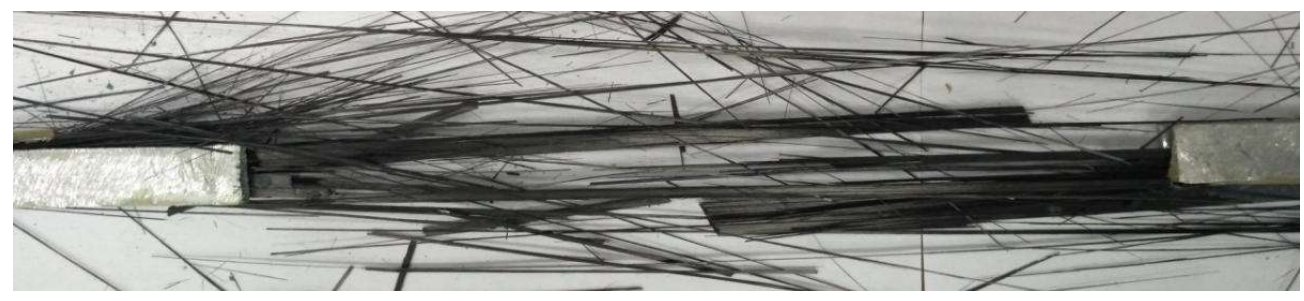

(c)

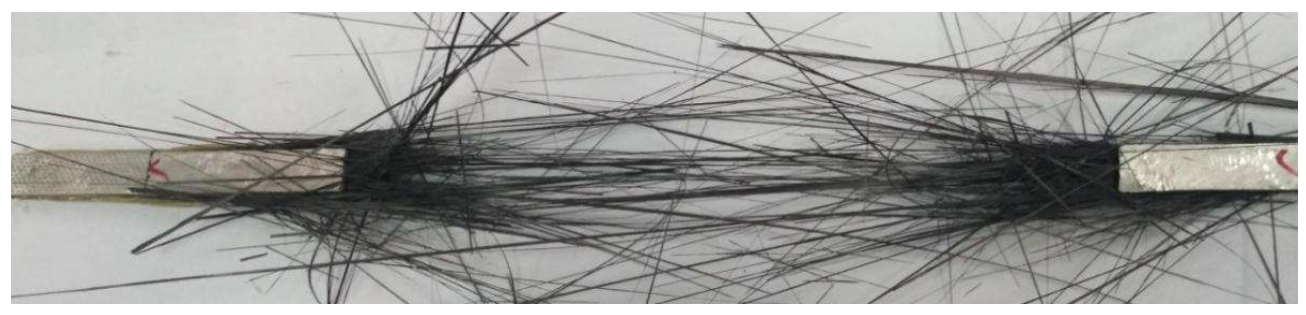

(d)

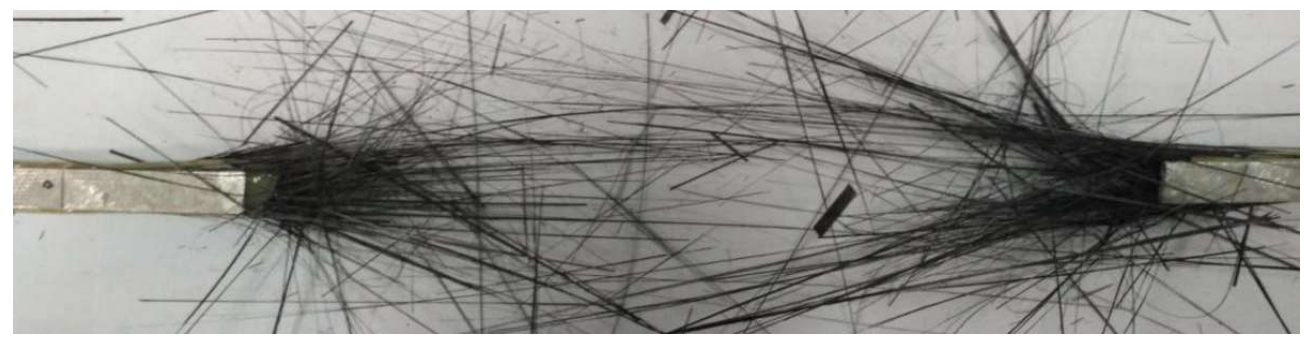

(e)

Figure 11. Failure mode of CFRP plate under different temperatures: (a) C-T10-4; (b) C-T30-6; (c) C-T50-2;

(d) C-T70-4; (e) C-T90-2 


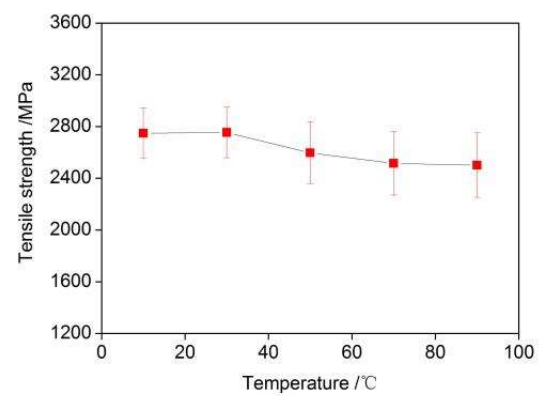

(a)

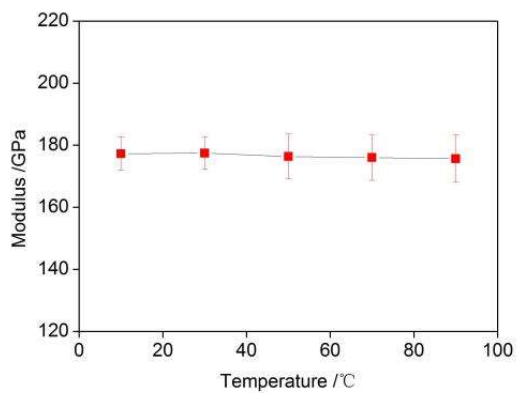

(b)

Figure 12. The effect of temperature on properties of CFRP plate: (a) tensile strength; (b) modulus.

\subsection{Effect of elevated temperatures on the properties of CFRP/steel double strap joint}

\subsubsection{Temperature effect on failure mode}

The failure mode of the steel/CFRP double strap joints was categorized into six modes [90]: (a) steel and adhesive interface debonding, (b) adhesive layer failure (cohesive failure), (c) CFRP and adhesive interface debonding, (d) CFRP delamination, (e) CFRP tensile rupture and (f) steel yielding. Typical failure mode are summarized in Figure 13. At $10{ }^{\circ} \mathrm{C}$, the CFRP adherend was entirely separated from the steel plate and there are small amount of carbon fibers attached to the steel surface, as seen in Figure 13a, i.e, joints failed mainly in mode (a). When temperature increased to $30{ }^{\circ} \mathrm{C}$, the failure of these joints can be defined as mode (d) - CFRP delamination, as shown in Figure 13b. when temperature increased to $50{ }^{\circ} \mathrm{C}$, the joints failed with mode (b), with part of the adhesive attached to steel plate and part of the adhesive attached to CFRP plate, as shown in Figure $13 \mathrm{c}$. For the joints at $70{ }^{\circ} \mathrm{C}$ and $90{ }^{\circ} \mathrm{C}$, they all failed due to the debonding between the CFRP and adhesive, as shown in Figures $13 \mathrm{~d}$ and e.

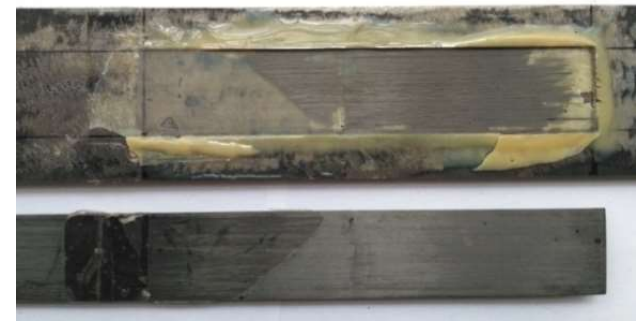

(a)

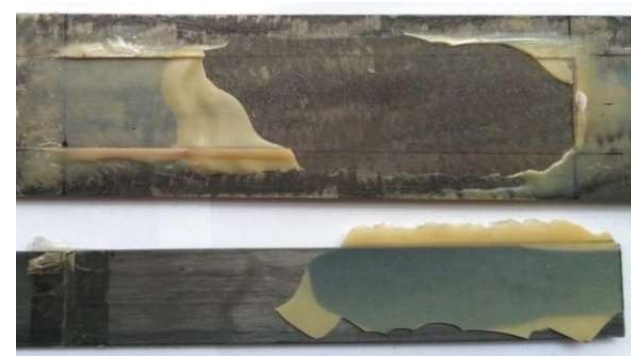

(c)

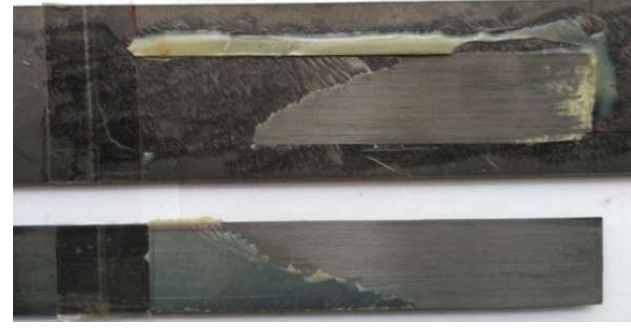

(b)

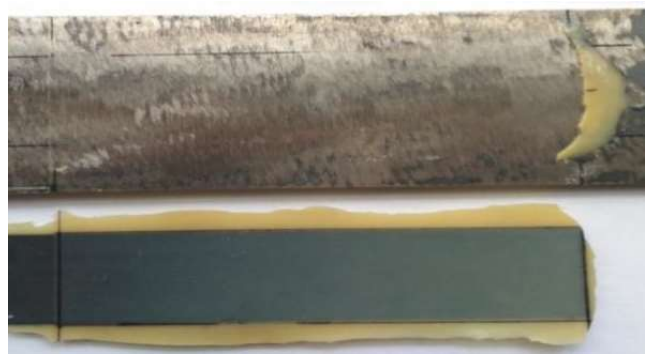

(d) 


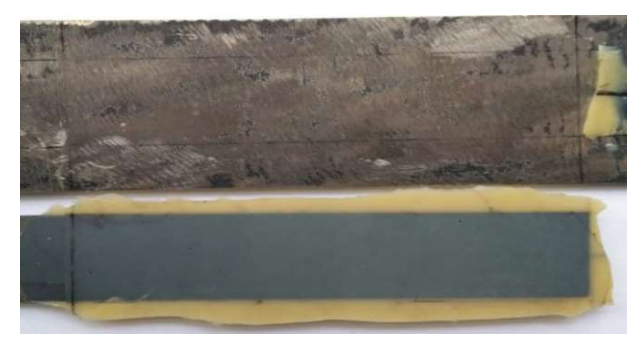

(e)

Figure 13. Failure modes of $\mathrm{CFRP} /$ steel double strap joints under different temperatures: C/S-T10-5; (b) C/S-T30-2; (c) C/S-T50-2; (d) C/S-T70-5; (e) C/S-T90-6.

(a)

\subsubsection{Temperature effect on joint stiffness}

Figure 14 shows the relationship between tensile load and joint displacement for the specimens at different temperatures. Apparently, these curves include two linear stage, and the slope of the first stage was much larger than that of the second one. After that, the load suddenly reduced to zero. In Figure 14, the slope of the curves is found to increase slightly when the temperature increased from $10^{\circ} \mathrm{C}$ to $30^{\circ} \mathrm{C}$, and then decrease when the temperature increased from $30{ }^{\circ} \mathrm{C}$ to 50 ${ }^{\circ} \mathrm{C}$ and higher values. This indicated that joint stiffness increased firstly and then decreased with temperature. This stiffness reduction is due to the stiffness degradation of the adhesive layer, being the weakest link under temperature effects. The values of slip at the ultimate load increased with the increasing of the temperature.

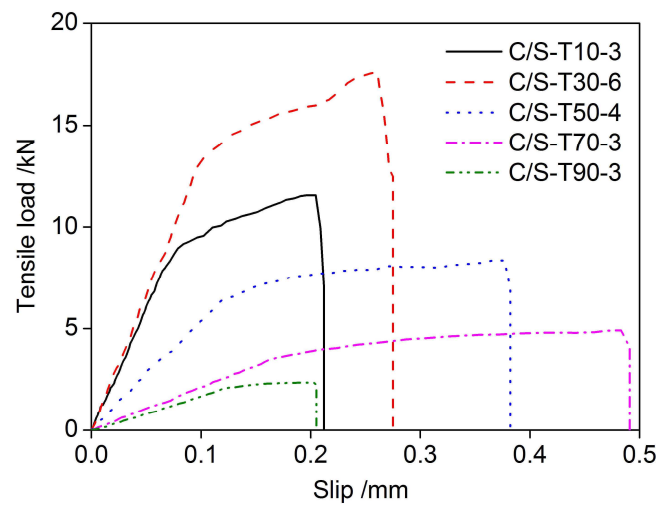

Figure 14. Typical tensile load vs.displacement curves for CFRP/steel double strap joints at different temperatures.

The stiffness of each joint at different temperatures was normalized by that at $30{ }^{\circ} \mathrm{C}$, i.e., dividing the slope of the load-displacement curve at different temperatures by that at $30{ }^{\circ} \mathrm{C}$, as shown in Figure 15. A much faster decrease can be observed when the temperature increased from $30{ }^{\circ} \mathrm{C}$ to $50{ }^{\circ} \mathrm{C}$. The joint stiffness was reduced by $57 \%$ when the temperature increased from $30{ }^{\circ} \mathrm{C}$ to $50{ }^{\circ} \mathrm{C}$. This is because when the temperature is around or over the glass transition, the shear modulus and the elastic modulus both degraded with the same trend. The degradation of stiffness shown in Figure 15 is mainly caused by the shear deformation of the adhesive layer [27]. 


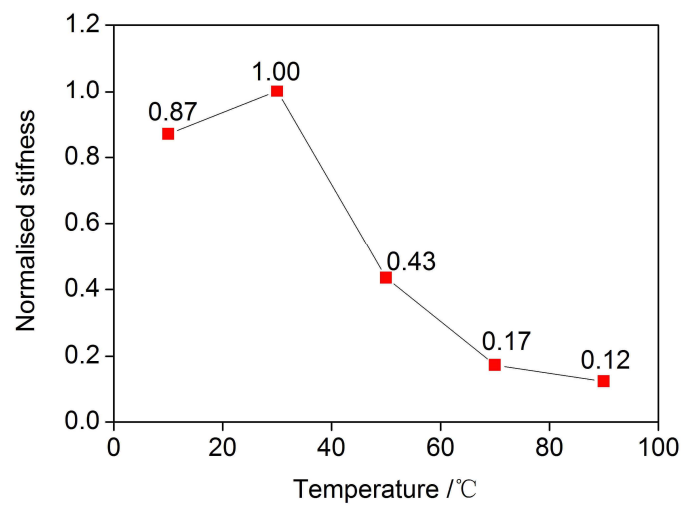

Figure 15. Normalized stiffness for CFRP/steel double strap joints.

\subsubsection{Temperature effect on tensile strength}

The ultimate tensile load of the joint under different temperatures are shown in Fig. 16, in which the values were given as an average load of the six specimens in each group. Apparently, the ultimate tensile load increased firstly and then decreased sharply with the increasing of temperature. The CFRP/steel double strap joints at $30{ }^{\circ} \mathrm{C}$ obtained the highest value $(36 \mathrm{kN})$. When the temperature increased to $50{ }^{\circ} \mathrm{C}$, the ultimate load experienced a $52.1 \%$ reduction comparing to that at $30{ }^{\circ} \mathrm{C}$. At $70{ }^{\circ} \mathrm{C}$ and $90{ }^{\circ} \mathrm{C}$, the ultimate load dropped by $71 \%$ and $88 \%$, respectively.

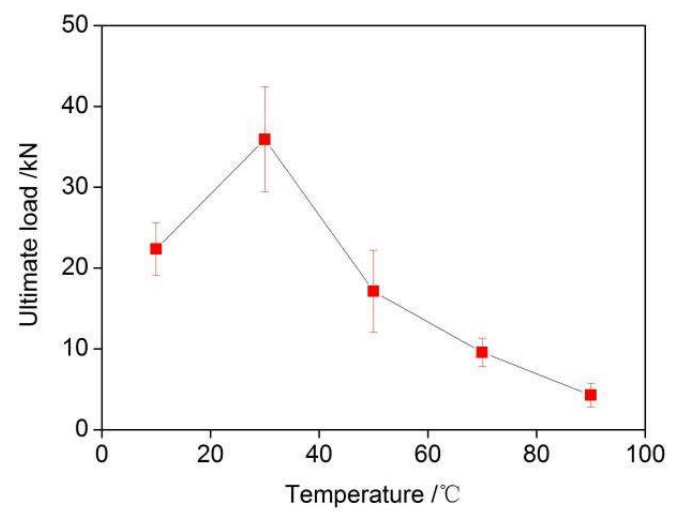

Figure 16. The effect of temperature on the tensile load of CFRP/steel double strap joints.

\subsubsection{Temperature effect on strain distribution}

The strain distribution of the CFRP plate at different load levels is presented in Figure 17. The strain of CFRP plate decreased with the increasing of the distance from the loaded end. With the increasing of the tensile load, the load was gradually transferred towards the free end. For the specimens at 10 and $30{ }^{\circ} \mathrm{C}$, the strains at the ultimate load were still zero, this means that the effective bond length was less than $115 \mathrm{~mm}$ and larger than $85 \mathrm{~mm}$. However, for the specimens at 70 and $90{ }^{\circ} \mathrm{C}$, the strains at the ultimate load were larger than zero, which indicated that the 
effective bond length was larger than $115 \mathrm{~mm}$. Thus, it can be concluded that the effective bond length increased with temperature, which is consistent with the results reported in Ref. [27]. In addition, The strains in the CFRP plate decreased significantly with the elevated temperature.

\subsubsection{Bond-slip curves}

Strain gauges bonded onto the CFRP plate were used to generate the data from which the interfacial bond-slip relationship was found. The bond stresses developed within the interface were calculated by assuming that the bond stress is constant between two consecutive strain gauges and the following expression was used:

$$
\tau(i)=E_{\mathrm{CFRP}} t_{\mathrm{CFRP}} \frac{\varepsilon_{\mathrm{CFRP}, i}-\varepsilon_{\mathrm{CFRP}, i-1}}{x_{i}-x_{i-1}},
$$

where $\tau(i)$ is the bond stress at points $x_{\mathrm{i}}, \varepsilon_{\mathrm{CFRP}, i}$ and $\varepsilon_{\mathrm{CFRP}, i-1}$ are the strains in the CFRP plate at points $x_{\mathrm{i}}$ and $x_{\mathrm{i}-1}$. The relative displacement between the CFRP and the steel plate allows the determination of the slip in the interface which can be determined as follows.

$$
s_{i}=\frac{x_{i}-x_{i-1}}{2}\left(\varepsilon_{0}+2 \sum_{j=1}^{i-1} \varepsilon_{j}+\varepsilon_{i}\right),
$$

where $S_{\mathrm{i}}$ is the slip between CFRP plate and steel plate at points $x_{\mathrm{i}}$ the bond stress at points $x_{\mathrm{i}}, \varepsilon_{0}$ is the strain in the CFRP plate at the free end, and set as zero and $\varepsilon_{\mathrm{j}}$ is the strain in CFRP plate at points $x_{\text {j. }}$.

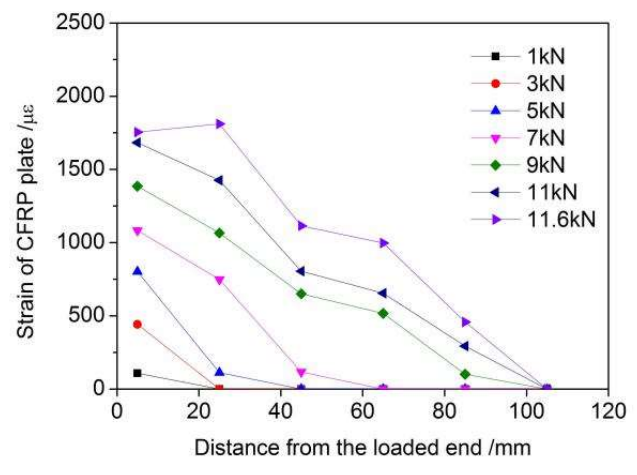

(a)

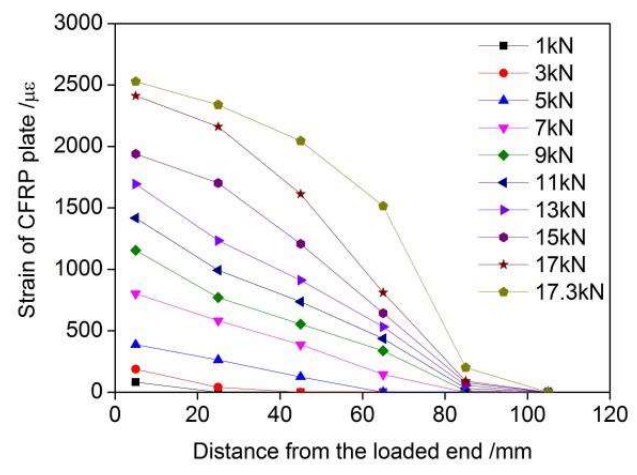

(b) 


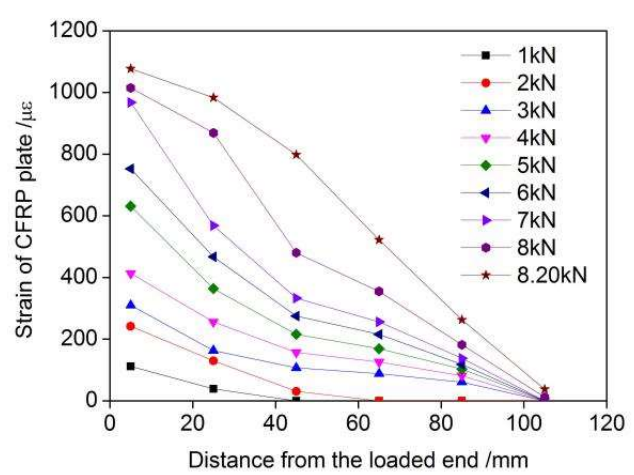

(c)

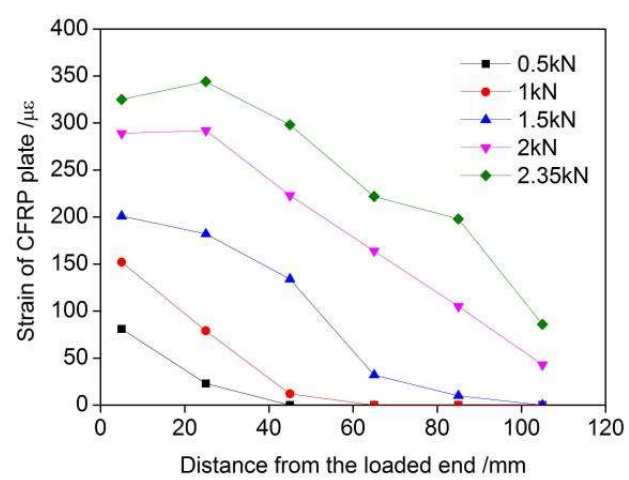

(e)

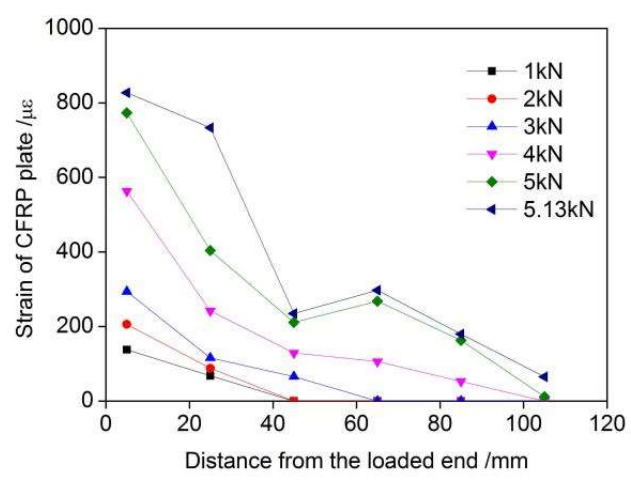

(d)

Figure 17. CFRP Stain distribution at different load: (a) C/S-T10-2; (b) C/S -T30-3; (c) C/S-T50-4; (d) C/S-T70-1; (e) C/S -T90-3.

As an example, it is shown in Figure 18 the relationships between the slip at different points and the bond stress of specimen C/T-10-3. The shape of the curves are similar and may be defined between bi-linear and a linear with an exponential softening, as described in the literarue for brittle substrates such as concrete [33,34], but a simple bi-linear shape is consistent with some previous findings reported in the literature in for CFRP-to-steel interfaces [35-37]. 


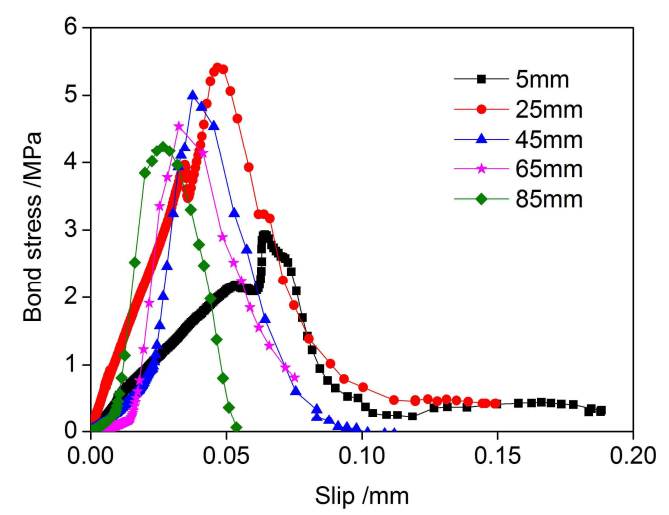

Figure 18. Bond-slip curves of specimen C/T-T10-3.

It should be noted that the bond stress is the average value between the two consecutive strain gauges. To predict the bond stress at any points along the CFRP plate, the applied tensile load and the slip at the loaded end are used to calculated by Dai et al. [38].

According to Ref. [38], the stress state can be shown in Figure 19. The relationship between the strain in CFRP plate at any points and the slip at this point can be expressed as follows.

$$
\varepsilon=f(s)
$$

where $\varepsilon$ is the strain of the CFRP plate at any points and $s$ is the slip between CFRP plate and steel plate at the corresponding point.
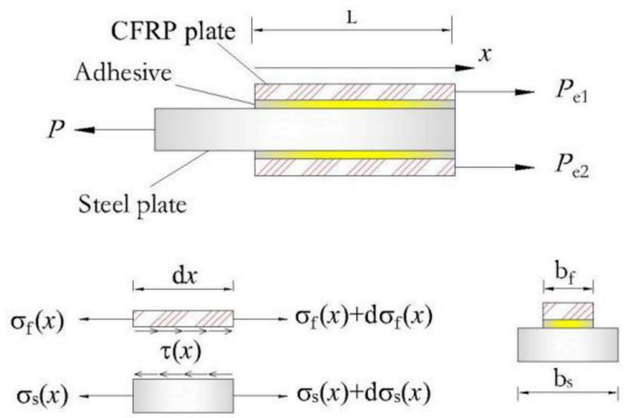

Figure 19. Schematic of the stress in the steel, CFRP and adhesive.

The first derivation with respect to $x$ of Eq. (3) is:

$$
\frac{d \varepsilon}{d x}=\frac{d f(s)}{d s} \cdot \frac{d s}{d x}=\frac{d f(s)}{d s} \cdot f(s),
$$

The bond stress at any points is 


$$
\begin{gathered}
\tau=E_{\text {CFRP }} t_{C F R P} \frac{d \varepsilon}{d x}=E_{\text {CFRP }} t_{C F R P} \cdot \frac{d f(s)}{d s} \cdot f(s), \\
\varepsilon=f(s)=A(1-\exp (1-B s)),
\end{gathered}
$$

where $A$ and $B$ are the coefficients based on the experiments, as shown in Table 4.

The prediction agrees well with the experimental, as shown in Figure 20.

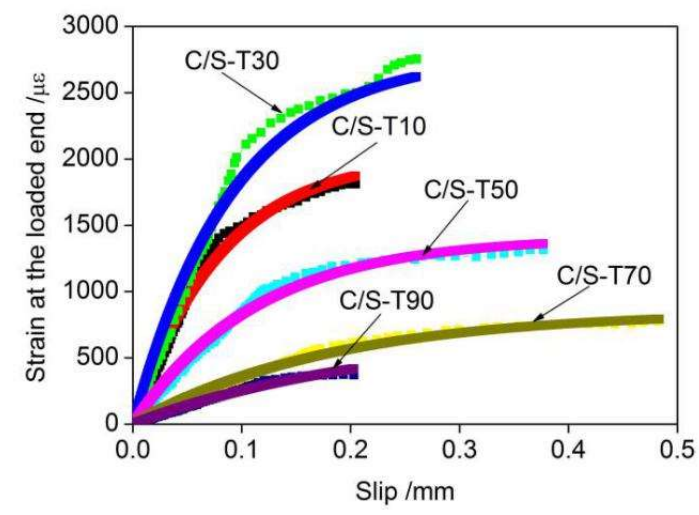

Figure 20. The comparison between the experimental results and prediction in terms of strain-slip curves.

The relationship between the values of A and B and the temperature is shown in Fig. 21 and can be expressed as follows.

$$
\begin{gathered}
\tau_{T}=A_{T}^{2} B_{T} E_{f} t_{f} e^{\left(-B_{T} s\right)\left(1-e^{-B_{T} s}\right)}, \\
\frac{A_{T}^{2}}{A_{30}^{2}}=e^{K(T-30)}, \\
B_{T}=-0.107 T+13.83
\end{gathered}
$$

where $\mathrm{K}=0.0317$, if $10 \leq T<30 ; \mathrm{K}=0.0643$, if $30 \leq T \leq 90$.
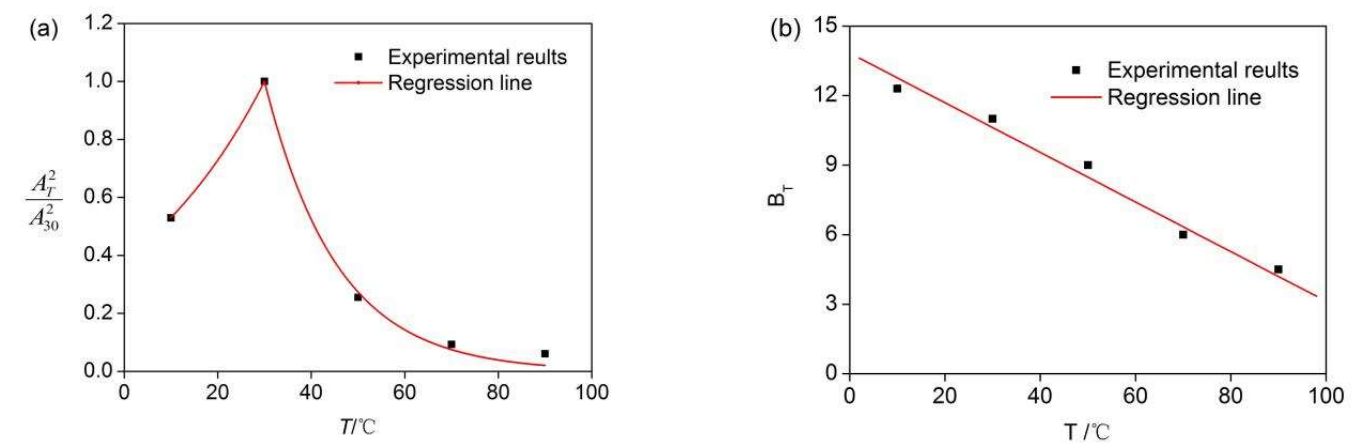
Figure 21. Regression line: (a) $A_{\mathrm{T}}$ and $T$; (b) $B_{\mathrm{T}}$ and $T$.

Author Contributions: Conceptualization, S.L. and N.L.; Methodology, S.L. and N.L.; Formal Analysis, C. L.; Investigation, C.L and T. Z.; Resources, C.L and T. Z.; Data Curation, C.L .; Writing-Original Draft Preparation, N.L.; Writing-Review \& Editing, N.L.; Project Administration, S.L. and N. L.

Funding: This research was funded by the National Natural Science Foundation of China (NSFC) (Grant number [51578428]) and Hubei Provincial Natural Science Foundation of China (Grant number [2016CFB271]).

Conflicts of Interest: The authors declare no conflict of interest.

\section{References}

1. Zhao, X.L.; Zhang L. State of the art review on FRP strengthened steel structures. Eng. Struct. 2007, 29, 1808-1823.

2. Bakis, C.E.; Bank, L.C.; Brown, V.L.; Cosenza, E.; Davalos, J.F.; et al. Fiber-reinforced polymer composites for construction state of-the-art review. J. Compos. Construct. 2002, 6, 73-87.

3. Linghoff, D.; Al-Emrani, M.; Kliger, R. Performance of steel beams strengthened with CFRP laminate-part 1: laboratory tests. Compos. Part B-Eng. 2010, 41, 509-515.

4. Dehghani, E.; Daneshjoo, F.; Aghakouchak, A.; Khaji, N. A new bond-slip model for adhesive in CFRPsteel composite systems. Eng. Struct. 2012, 34, 447-454.

5. Fawzia, S.; Zhao, X.L.; Al-Mahaidi, R. Bond-slip models for double strap joints strengthened by CFRP. Compos. Struct. 2010, 92, 2137-2145.

6. Fawzia, S.; Al-Mahaidi, R.; Zhao, X.L. Experimental and finite element analysis of a double strap joint between steel plates and normal modulus CFRP. Compos. Struct. 2006, 75, 156-162.

7. Fawzia, S.; Zhao, X.L.; Al-Mahaidi, R.; Rizkalla, S. Bond characteristics between CFRP and steel plates in double strap joints. Adv. Steel Construct. Int. J. 2005, 1,17-28.

8. Lu, Y.Y.; Zhang, H. J.; Liu, S. L. A study on the adhesive shear performance of steel plates bonded by carbon fiber reinforced polymer. China Civ. Eng. J. 2006, 39, 60-67.

9. Miller, T.C.; Chajes, M.J.; Mertz, D.R.; Hastings, J.N. Strengthening of a Steel Bridge Girder Using CFRP Plates. J. Bridge Eng. 2001, 6, 514-522.

10. Bai, Y.; Zhao, X.L.; Al-Mahaidi, R. Post yielding behaviour of CFRP Steel adhesive joints under static and cyclic loading. In: 5th international conference on thin walled structures, Brisbane, June 2008.

11. Wu, C.; Zhao, X.L.; Al-Mahaidi, R.; Duan, W.H. Experimental study on bond behaviour between UHM CFRP laminate and steel. In: The 5th international conference on FRP composites in civil engineering, Beijing, 27-29 September 2010.

12. Schnerch, D.; Dawood, M.; Rizkalla, S.; Sumner, E.; Stanford, K. Bond behavior of CFRP strengthened steel structures. Adv. Struct. Eng. 2006, 9, 805-817.

13. Chiew, S.P.; Yu, Y.; Lee, C.K. Bond failure of steel beams strengthened with FRP laminates-part 1: model development. Compos. Part B-Eng. 2011, 42, 1114-1121.

14. Al-Shawaf, A.; Al-Mahaidi, R.; Zhao, X.L. Effect of elevated temperature on bond behaviour of high modulus CFRP/steel double-strap joints. Aust. J. Struct. Eng. 2009, 10, 63-74. 
15. American Concrete Institute (ACI). Guide for the design and construction of externally bonded FRP systems for strengthening concrete structures. American Concrete Institute Rep. ACI 440.2R-08, Farmington Hills, MI.

16. Bai, Y; Keller, T. Effects of thermal loading history on structural adhesive modulus across glass transition. Constr. Build. Mater. 2011, 25, 2162-2168.

17. Michels, J.; Widmann, R.; Czaderski, C.; Allahvirdizadeh, R.; Motavalli, M. Glass transition evaluation of commercially available epoxy resins used for civil engineering applications. Compos. Part B-Eng. 2015, 77, 484-493.

18. Bai, Y.; Keller, T.; Vallee, T. Modeling of stiffness of FRP composites under elevated and high temperatures. Compos. Sci Technol. 2008, 68, 3099-3106.

19. Chowdhury, E. U.; Eedson, R.; Green, M.F.; Bisby, L. A.; Benichou, N. Mechanical characterization of fibre FRP materials at high temperature. Fire Tech. 2011, 47, 1063-1080.

20. Bai, Y.; Keller, T. Modeling of strength degradation for fiber reinforced polymer composites in fire. $J$. Compos. Mater. 2009, 43, 2371-2385.

21. Bai, Y.; Keller, T. Pultruded GFRP tubes with liquid-cooling system under combined temperature and compressive loading. Compos. Struct. 2009, 90, 115-121.

22. Bai, Y.; Keller, T. Effects of thermal loading history on structural adhesive modulus across glass transition. Constr. Build. Mater. 2011, 25, 2162-2168.

23. Kodur, V.K.R.; Bisby, L.A.; Green, M.F. Preliminary guidance for the design of FRP-strengthened concrete members exposed to fire. J. Fire Prot. Eng. 2007, 17, 5-26.

24. Liu, H., Zhao, X.L., Bai, Y.; Singh, R.; Rizkalla, S.; Bandyopadhyay, S. Bond tests of high modulus CFRP/steel double-strap joints at elevated temperatures. Proc., 6th Int. Composites Conf. (ACUN-6): Composite and Nanocomposites in Civil, Offshore and Mining Infrastructure, Monash Univ., Clayton, Australia, 2012, pp. 139-145.

25. Klamer, E. L., Hordijk, D. A., and Hermes, M. C. J. The influence of temperature on RC beams strengthened with externally bonded CFRP reinforcement. Heron, 2008, 53, 157-186.

26. Zhu, D.J.; Yao, M.X.; Zhang, H.A.; Huo, X.F. Temperature effect on the mechanical properties of CFRP /Steel single-lap shear joints under dynamic tensile loading. China Civ. Eng. J. 2016, 49, 28-35.

27. Nguyen, T.C.; Bai, Y.; Zhao, X.L.; Al-Mahaidi, R. Mechanical characterization of steel/CFRP double strap joints at elevated temperatures. Compos. Struct. 2011, 93, 1604-1612.

28. Nguyen, T. C., Bai, Y., Al-Mahaidi, R., and Zhao, X. L. Time dependent behaviour of steel/CFRP double strap joints subjected to combined thermal and mechanical loading. Compos. Struct. 2012, 94, 1834-1845.

29. Agarwal, A,; Foster S.J.; Hamed, E. Testing of new adhesive and CFRP laminate for steel-CFRP joints under sustained loading and temperature cycles. Compos. Part B-Eng. 2016, 99, 235-247.

30. Standardization Administration of the People's Republic of China. Test methods for properties of resin casting body; GB/T 2567-2008; Standardization Administration of the People's Republic of China: Beijing, China, 2008

31. ISO Standard. Plastics*/Determination of tensile properties*/Part 2: test conditions for moulding and extrusion plastics Reference; ISO 527-2 1993.

32. The State Bureau of Quality and Technical Supervision. Test method for tensile properties of oriented fiber reinforced plastics; GB/T 3345-1999; The State Bureau of Quality and Technical Supervision: Beijing, China, 1999. 
33. Caggiano, A.; Martinelli, E. A fracture-based interface model for simulating the bond behavior of FRP strips glued to a brittle substrate. Compos. Struct. 2013, 99, 397-403.

34. Caggiano, A.; Schicchi, D.S. A thermo-mechanical interface model for simulating the bond behavior of FRP strips glued to concrete substrates exposed to elevated temperature. Eng. Struct. 2015, 83, 243-251.

35. Yang, Y.; Biscaia, H.; Chastre, C.; Silva, M.A.G. Bond characteristics of CFRP-to-steel bonded joints. J. Constr. Steel Res. 2017, 138, 401-419.

36. Yu, T.; Fernando, D.; Teng, J.G.; Zhao, X.L. Experimental study on CFRP-to-steel bonded interfaces. Compos. Part B-Eng. 2012, 43, 2279-2289.

37. Fawzia S, Zhao XL, Al-Mahaidi R. Bond-slip models for double strap joints strengthened by CFRP. Compos. Struct. 2009, 92, 2137-2145.

38. Dai, J.G.; Ueda, T.; Sato, Y. Development of the nonlinear bond stress-slip model of fiber reinforced plastics sheet-concrete interfaces with a simple method. J. Compos. Construct. 2005, 9, 52-62. 